\title{
Development
}

\section{Facilitating partnership working in public health: evaluation of a clinical service development approach}

\author{
Cath Jackson ${ }^{1}$, Susan Blundell ${ }^{2}$, Rosemary R.C. McEachan ${ }^{3}$ and lan Cameron ${ }^{2}$ \\ ${ }^{1}$ School of Healthcare, University of Leeds, Leeds, UK \\ ${ }^{2}$ Leeds Primary Care Trust, Leeds, UK \\ ${ }^{3}$ Institute of Psychological Sciences, University of Leeds, Leeds, UK
}

\begin{abstract}
Background: UK health policy identifies partnership working as fundamental to tackling health inequalities. Related to this is the development of a multi-disciplinary public health workforce, including an increase in the public health role of primary care nurses. Within this policy context, a primary care trust in the north of England established a community health team (CHT) in September 2005 to improve intra- and inter-agency working for public health. The Clinical Microsystems (CMS) framework informed the process of development, an approach not previously applied to public health. Aim: This paper describes an evaluation of the $\mathrm{CHT}$ and presents the key lessons learnt in terms of what worked and did not work in the context of the CMS framework. Methods: Participants were members and wider stakeholders of the $\mathrm{CHT}$ from three professional groups: individuals holding relevant strategic posts in the Public Health and Nursing Directorates within the Primary Care Trust, health visitors and school nurses, and voluntary sector staff. Focus group ( $n=9$ focus groups) and postal questionnaire $(n=21)$ data were collected at baseline, 6 and 12 months post-implementation. Participants' views on the implementation of the $\mathrm{CHT}$ were explored within the 'five $\mathrm{Ps}^{\prime}$ (purpose, population, people, processes and patterns) of the CMS framework. Findings: Six themes emerged from the focus group data that illustrated key issues for the implementation of the $\mathrm{CHT}$ : 'agreeing the focus,' 'strong leadership,' 'the challenge of communication,' 'managing workloads and new ways of working,' 'success of the $\mathrm{CHT}^{\top}$ and 'outside influences.' Communication and heavy workloads were identified as key barriers to the success of the $\mathrm{CHT}$ in the questionnaire data. These data highlight the complex and evolving nature of public health partnership working and identify important issues that might usefully be considered in future initiatives of this kind.
\end{abstract}

Key words: clinical microsystems; partnership working; primary care trust; public health

Received 1 March 2008; accepted 12 January 2009; first published online 6 April 2009

Correspondence to: Dr Cath Jackson, School of Healthcare, University of Leeds, Leeds LS2 9UT, UK. Email: c.j.jackson@ leeds.ac.uk

\section{Introduction}

UK health policy consistently identifies partnership working as fundamental to tackling the complex, multi-faceted causes of health inequalities 
(Department of Health, 2000; 2001a; 2003; 2004; 2006). Central to delivering partnership working and the public health agenda are Primary Care Trusts (PCT; Department of Health, 2000). These are legally established statutory National Health Service (NHS) bodies with responsibilities including improving the health of the population, planning, commissioning as well as the delivery of primary and community health services in partnership' with local authorities, voluntary agencies and local communities (Department of Health, 2000; 2002). Key elements of this approach have been the development of a multi-disciplinary public health workforce, increased partnership working at the local level and a move to increase the public health role of the primary care nursing workforce, including health visitors and school nurses (Department of Health, 1999; 2001b; 2004; World Health Organization, 2000; Royal College of Nursing, 2007). This role involves supporting people to live healthy lives, engaging communities, empowering individuals and ensuring services are equitable.

Within this policy context, in April 2004, a PCT in the northwest area of a large city in West Yorkshire, England employed a Public Health Nurse Facilitator (SB) to develop the public health role of nurses within the organization. The PCT served a population of 170000 of both affluence and deprivation (Director of Public Health, 2004). It quickly became evident that health practitioners were having difficulty in engaging and working locally with other sectors (eg, the voluntary sector) on public health priorities. What appeared to be required was a 'support mechanism' to enable health practitioners, including nurses, to work in partnership, both within and outside the PCT, to better address health inequalities and health improvements in local communities. A community health team (CHT) was, therefore, established in September 2005.

The CHT was defined by the PCT as 'a co-ordinated, structured network of health practitioners and relevant agencies, developed to facilitate partnership working in a defined geographical or topic area which is linked formally to the Public Health Directorate to deliver interventions to address health inequalities.' It had five aims: (1) Address health inequalities by working in partnership to deliver interventions in a defined geographical patch or topic area; (2) Create a co-ordinated, structured network of health practitioners and other agencies working in partnership; (3) Support the development of the public health wider workforce; (4) Create a programme of work that is needs-led; and (5) Formally link the work of the Public Health Directorate with 'grass root' staff and local initiatives.

The underpinning framework used by the PCT in the process of developing the CHT was the Clinical Microsystems (CMS) framework (Dartmouth Hitchcock Medical Centre, 2007). This framework was originally developed in the US to facilitate service improvement by clinical teams. It has now been adapted to be relevant to the UK health system and has evaluated favourably across eight pilot (hospital) sites in England (Golton and Wilcock, 2005). The authors of this evaluation conclude that the CMS framework can improve service delivery in these clinical settings. Furthermore, they suggest that this approach might usefully be applied to 'whole community approaches that cross social and heath care boundaries' (p. 3). To date, the CMS has not been applied in the field of public health.

A CMS is defined as '...the small, functional, front-line units that provide most healthcare to most people. They are the essential building blocks of the health system. They are the place where patients and health care staff meet' (Dartmouth Hitchcock Medical Centre, 2007). The purpose of the CMS framework is to help members within a microsystem (in our case, within the CHT) to build self-awareness of other members; comprehensively examine current structure and functioning; develop an understanding of the systems and processes that connect teams, as well as the broader system within which they work; and to identify and address areas for improvement (Golton and Wilcock, 2005). Activities are guided by the 'five Ps' (purpose, patients, people, processes and patterns) that describe the key components of the work of the microsystem. Figure 1 provides an overview of the development of the CHT in the context of this CMS framework. 'Patients' was changed to 'Population' for the purpose of the CHT, as the focus was public or population health rather than the health of patients in a clinical setting.

In terms of developing the CHT, there were two main reasons why the CMS framework was chosen. First, health and social care organizations 


\begin{tabular}{lll}
\hline $\mathbf{P}$ & Description of the 'P' & Developing and progressing the CHT \\
\hline Purpose & (a) What is the purpose of this team? & $\begin{array}{l}\text { (a) The specific public health focus for the CHT (oral health of } \\
\text { children/young people) was agreed with all members and wider } \\
\text { stakeholders in a workshop at the outset of the CHT. It was decided } \\
\text { that the focus needed to be timely (in the context of health and }\end{array}$ \\
& $\begin{array}{l}\text { social care policy), delivered using a partnership approach and for } \\
\text { which there were currently gaps in local provision. Individuals' local } \\
\text { knowledge as well as existing local health needs analyses, indices } \\
\text { of multiple deprivation and City Council Area Plans informed this } \\
\text { process. }\end{array}$ \\
&
\end{tabular}

(b) What are we providing?
Population
(a) Who has the greatest need?

(b) How are we involving families/children/young people in the development of our work?

People (a) Who is in our team?

Processes (a) What are the core processes that underpin the work of our team? What works well and what needs improving?

(b) How do we as a team get things done?

$\begin{array}{ll}\text { Patterns } & \text { (a) What does the data suggest about the team's }\end{array}$ performance?

(b) How do things change over time and how does our service respond to these changes?

How do people feel about working in our team? How do we support each other in our work and recognise and reward good work? (b) The CHT agreed that they would provide consistent, evidencebased oral health promotion messages to the target population; incorporate these oral health promotion messages into their existing work to provide continuity; and share resources and expertise to maximise the skill base of the $\mathrm{CHT}$. In addition, two specific oral health projects were undertaken: a health promotion campaign 'Bin the Bottle' (see Figure 2) and an oral health educators programme.

(a) Greatest need was identified from existing health needs assessments and local data. The target population was identified as children/young people living within a designated area of the city (within the 20\% lowest Super Output Area nationally; Office of Deputy Prime Minister, 2004).

(b) Existing health needs assessments that had collected parents'/carers' views on oral health of children/young people were used to inform the development of the $\mathrm{CHT}$ work.

(a) CHT members were identified by the Public Health Nurse Facilitator. They were individuals from three professional groups (individuals holding relevant strategic posts within the Public Health and Nursing Directorates in the PCT, health visitors and school nurses, voluntary sector staff) who worked across the designated area of the city and/or the identified public health topic.

(b) Bi-annual half day away days were held to enable $\mathrm{CHT}$ members to discuss working in this team, support each other in their work, celebrate good work and team build. Priorities and problems were identified, solutions found and direction created. A weekly enewsletter was circulated to update all members on the progress of the CHT.

(a) To identify the core processes underpinning the $\mathrm{CHT}$ a mapping exercise was undertaken to identify members' targets, working practices, restrictions, existing and potential input and opportunities for joint working in the context of oral health of children/young people.

(b) To 'get things done', an action plan for the three professional groups to deliver work together was created. The rationale was that the synergy created by the combination of expertise from the wide variety of partner agencies would achieve greater impact on the local community than lone agency working.

(a) An independent evaluation of the $\mathrm{CHT}$ explored the performance of the $\mathrm{CHT}$ in its first 12 months.

(b) Given the evolving nature of the CHT changes were made to processes (e.g. communication) as problems were identified by the evaluation.

Figure 1 How the Clinical Microsystems framework informed the process of implementing the Community Health Team

are made up of complex and diverse systems that operate at different levels, for example, referral systems for individual episodes of care and PCT systems for developing strategies for identifying local priorities for commissioning services. The microsystem is judged to be the level that has the biggest impact on patient experience. It is viewed as 'the most effective place to work to achieve 
widespread change whilst ensuring that improvement remains practical, relevant and manageable' (Department of Health, 2005, p. 9). As such, this framework appeared to operate at the 'level' for achieving greatest improvement in public health. Second, it provided a 'structure' that ensured that a comprehensive range of issues pertinent to the development of a new team were considered from the start.

An independent evaluation of the CHT in its first 12 months was undertaken (by CJ and RMc) to ensure that the lessons learnt, including the use of the CMS framework (Dartmouth Hitchcock Medical Centre, 2007), were transferred across the wider PCT. The findings of the evaluation are the focus of this paper.

\section{Methods}

\section{Study design}

Focus groups and postal questionnaires were used to explore issues relating to the CHT implementation at baseline (when the CHT was established), and at 6 and 12 months post-implementation. Ethics approval was not sought, as the CHT was about modernizing the existing service through working in new ways.

\section{Participants}

Participants were CHT members and wider stakeholders from three professional groups: (i) individuals holding relevant strategic posts in the Public Health and Nursing Directorates within the PCT (eg, Director of Public Health (IC), Lead Nurse, Locality Development Manager, Health Improvement Manager and Public Health Programme Manager), (ii) health visitors and school nurses, and (iii) voluntary sector staff. These individuals were identified by the Public Health Nurse Facilitator as working in the designated area of the city and/or the identified public health topic area for the CHT.

\section{Data collection}

Three focus groups with CHT members were held at each time point (nine in total). The postal questionnaires were distributed to $\mathrm{CHT}$ members and wider stakeholders at these times. The focus group topic guides and the postal questionnaires probed CHT members' and wider stakeholders' views on the implementation of the CHT over time. These issues were explored within the 'five Ps' of the CMS framework. Example questions included 'what do you consider is the purpose of the CHT?' (purpose), 'how well is the CHT engaging with the target community?' (population), 'how well are the different professional groups working together?' (people), 'are there any barriers that you feel are hindering the CHT?' (processes) and 'what would you say are going to be the key indicators of success of the CHT?' (patterns). The focus groups were audio-taped and fully transcribed.

\section{Data analysis}

Descriptive content analysis was used to identify key themes that emerged from the focus group data relating to the implementation of the $\mathrm{CHT}$ within the context of the 'five Ps' of the CMS framework. First, CJ and RMc worked independently to identify descriptive themes emerging from the data. They then met to discuss and agree on the themes that captured participants' perspectives pertaining to the 'five Ps'. Similarities and differences in views within and between the three professional groups were explored over the three time points. Analysis of the questionnaire data was undertaken using SPSS version 12. Means and standard deviations were calculated. Given the small number of participants, questionnaire data from the three professional groups were combined and analysed together.

\section{Evaluation of 'Bin the Bottle'}

A significant piece of work undertaken by the CHT in its pilot year was an oral health promotion campaign - 'Bin the Bottle' (see Figure 2). As part of the evaluation of the CHT, the intention was to collect data, pre- and post-campaign, on parents' awareness, knowledge, attitudes and behaviour with regard to the Bin the Bottle message. These were considered to be 'proxy' measures of potential effectiveness of the campaign since changes in oral health (eg, reduction in caries) were unlikely to occur in the 12 months of the evaluation (Fuller, 1999). The CHT members and wider stakeholders were asked to distribute a short questionnaire to parents; however, response was poor and it was not possible to use these data in any meaningful way. Instead, CHT 
'Bin the Bottle' was a two-week health promotion campaign that aimed to promote the following oral health messages to parents of children under three years of age.

- Aim to change over from bottle to cup by your child's first birthday, this will protect teeth and help to establish good eating patterns

- Children are less likely to drink continuously from a cup than a bottle

- Give your child plenty of encouragement to learn to drink from a cup

- Milk and water are the drinks of choice

- Cool kids use cups

- Using a cup will help to give your child a great smile

For two weeks in May $2006 \mathrm{CHT}$ members promoted these messages and distributed feeder cups, leaflets and stickers to parents in a variety of local community venues e.g. community groups, health centres, libraries and supermarkets. Parents were encouraged to exchange their children's bottles and dummies (which were placed in the big red bins of the campaign) for feeder cups.

At the end of the two-week period 'Bin the Bottle' messages were incorporated into CHT members' ongoing work with families.

Figure 2 'Bin the Bottle'

members and wider stakeholders were asked for their views and reflections on the 'success' of Bin the Bottle (presented further in 'patterns').

\section{Results}

\section{Participants}

A total of 25 CHT members participated in at least one focus group (see Table 1). This number of participants is higher than the number of CHT members identified at baseline $(n=18)$. Due to work commitments and staff turnover it was not possible for all individuals, who were originally invited, to attend all of the focus groups over the duration of the evaluation. When this occurred, their colleagues attended instead (increasing the number to 25). However, there was some consistency of participants over time, with $12 \mathrm{CHT}$ members attending at least two of the three focus groups.

A total of 21 (of a maximum 31) CHT members and wider stakeholders completed at least one postal questionnaire, and 10 completed all three questionnaires. The response rates at baseline, 6 and 12 months were $57 \%, 67 \%$ and $100 \%$ (strategic post holders in PCT); $47 \%, 71 \%$ and $60 \%$ (health visitors and school nurses) and 67\%, 44\% and $56 \%$ (voluntary sector staff).

\section{Implementation of the CHT}

Analysis of the qualitative data revealed six themes that illustrated key issues for the 
Table 1 Focus group participants

\begin{tabular}{|c|c|}
\hline \multicolumn{2}{|l|}{ Baseline } \\
\hline $\begin{array}{l}\text { Focus } \\
\text { group } 1\end{array}$ & Eight strategic PCT \\
\hline $\begin{array}{l}\text { Focus } \\
\text { group } 2\end{array}$ & Three health visitors \\
\hline & Two school nurses \\
\hline & Two student nurses \\
\hline $\begin{array}{l}\text { Focus } \\
\text { group } 3\end{array}$ & Three voluntary sector \\
\hline \multirow{5}{*}{$\begin{array}{l}6 \text { months } \\
\text { Focus } \\
\text { group } 4 \\
\text { Focus } \\
\text { group } 5\end{array}$} & \\
\hline & $\begin{array}{l}\text { Two strategic PCT (both had attended } \\
\text { the focus group at baseline) }\end{array}$ \\
\hline & Three health visitors \\
\hline & Two school nurses \\
\hline & $\begin{array}{l}\text { One nursing assistant (three had attended } \\
\text { the focus group at baseline) }\end{array}$ \\
\hline $\begin{array}{l}\text { Focus } \\
\text { group } 6\end{array}$ & $\begin{array}{l}\text { Five voluntary sector (three had attended } \\
\text { the focus group at baseline) }\end{array}$ \\
\hline \multicolumn{2}{|l|}{12 months } \\
\hline $\begin{array}{l}\text { Focus } \\
\text { group } 7\end{array}$ & $\begin{array}{l}\text { Four strategic PCT (all four had attended } \\
\text { the focus group at baseline only) }\end{array}$ \\
\hline \multirow{3}{*}{$\begin{array}{l}\text { Focus } \\
\text { group } 8\end{array}$} & Three health visitors \\
\hline & One school nurses \\
\hline & $\begin{array}{l}\text { One nursing assistant (four had attended a focus } \\
\text { group at baseline and/or at six months) }\end{array}$ \\
\hline $\begin{array}{l}\text { Focus } \\
\text { group } 9\end{array}$ & $\begin{array}{l}\text { Four voluntary sector (three had attended a } \\
\text { focus group at baseline and/or at six months) }\end{array}$ \\
\hline
\end{tabular}

$\mathrm{PCT}=$ Primary Care Trust. implementation of the CHT within the 'five Ps' of the CMS framework. A number of these descriptive themes related to more than one ' $\mathrm{P}$ ' (see Figure 3). Selected quotations are provided verbatim to illustrate each theme. Quantitative data (elicited from the postal questionnaire) pertaining to themes are also presented.

\section{Purpose}

The process of 'agreeing the focus' of the CHT was a theme that emerged across two of the "five Ps': purpose and population (discussed further). Agreeing the specific focus on oral health in children/young people amongst CHT members and wider stakeholders was important to all three (professional) groups if for slightly different reasons. Strategic post holders in the PCT alluded to an underlying philosophy of the CHT to engage CHT members and stakeholders in this process. Whereas the health visitors, school nurses and voluntary sector staff liked that their expertise was being valued. They readily identified their skills that they felt could (and should) be used:

I think we should be involved in planning. Absolutely because we are the main people who know what the needs are.

(Health visitor, FG2)

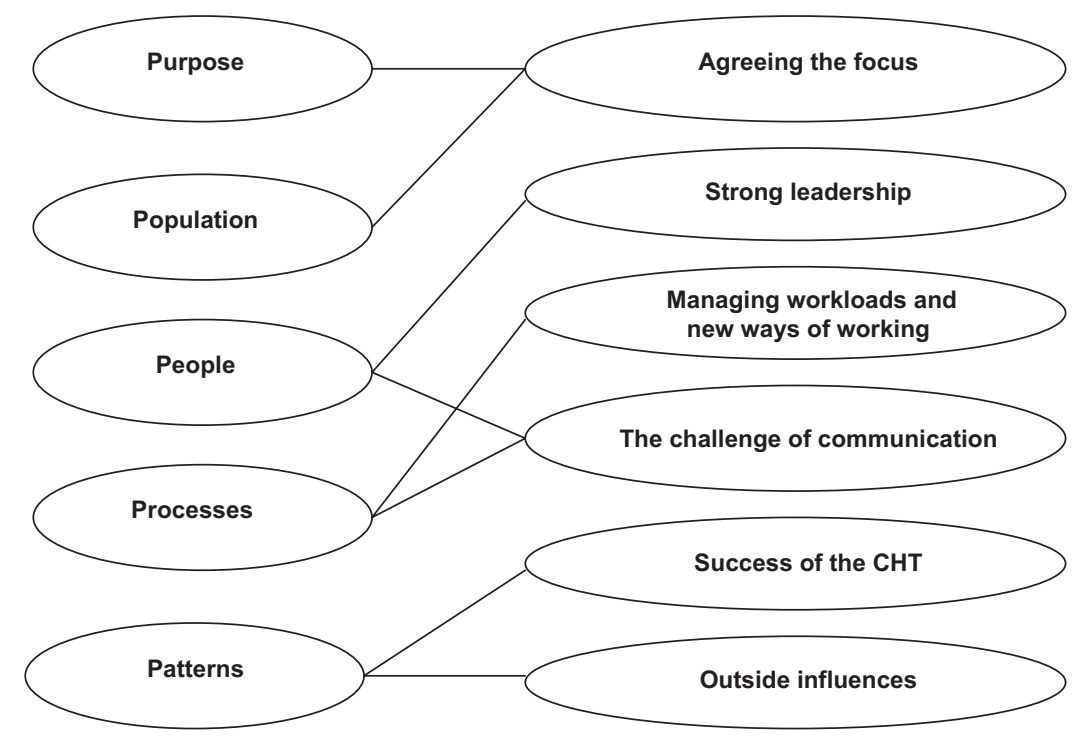

Figure 3 Emergent themes

Primary Health Care Research \& Development 2009; 10: 177-188 
Having a specific focus was unanimously seen as useful in bringing together the different professional groups with a common objective, and a way of securing success on a small scale from which to build in the future. Furthermore, the health visitors and school nurses stated that having this oral health goal meant that they had made a concerted effort to talk about oral health with parents, which they may not have done previously. However, at 12 months post-implementation, all three groups felt that the focus had become too narrow, particularly regarding the 'Bin the Bottle' campaign. The health visitors and school nurses felt that the range of oral health messages that they could have disseminated to parents had been limited. The narrow focus had excluded some voluntary sector staff, as their work remit, dictated by their funder, did not include this young age group or this particular health issue:

I think it seemed like a good idea at the time (to focus on oral health of children/young people) because it was very broad and it was good to narrow it down and focus though it did potentially exclude some organisations and maybe the message then became too narrow.

\section{(Voluntary sector staff, FG9)}

\section{Population}

All three groups agreed at 12 months postimplementation that the target community (ie, families, children and young people) had not been involved in identifying the specific focus of the CHT. However, they disagreed on the importance of this. Strategic post holders in the PCT typically commented that whilst the community had not been formally engaged in the process, a certain level of community engagement had occurred in using existing health needs assessments and CHT members' community knowledge. Furthermore, they considered that for this first year of the CHT the overriding aim was to change the way that the CHT members worked in the area of child health and health inequalities:

I think we did a deliberate approach to work with the staff. You know an alternative approach would have been, say we want staff to change the way they work and the way we're going to use is getting staff to be challenged by service users...I think in future years, I mean you can see it (involving the target community) being a sort of starting point but we're not there yet.

(Strategic post holder in PCT, FG7)

The health visitors and school nurses talked about the focus on oral health of children/young people being evidence-based and informed by their own knowledge that was gained from their interaction with the community. In contrast, the voluntary sector felt that families, children and young people should have been consulted. It was clear from the discussion that their usual way of working would be to fully engage with the community:

At the end of the day the impact is supposed to be in the community and if they weren't getting across to the community then it's not practical, so it's about involving the community more.

(Voluntary sector staff, FG9)

\section{People}

Two themes emerged. The first theme was 'strong leadership.' There was clear consensus that strong leadership from the Public Health Nurse Facilitator was vital to the progress of the CHT. Focus group participants talked about this individual's enthusiasm, energy and commitment, and agreed that she was the driving force behind the CHT. It seemed also to be important to the health visitors, school nurses and voluntary sector staff that one individual had specific responsibility within their work remit for leading the CHT, as this, they assumed, would mean that the individual had allotted time to undertake this important role. This was seen as being different to their own situations whereby CHT work was additional to their existing workloads (discussed further):

I think strong management...you need someone with enthusiasm and drive to actually keep it going and I think whoever's job it is they actually need time in their work week to be able to actually give it the time it deserves.

(Voluntary sector staff, FG3)

Interestingly, individuals holding strategic posts within the PCT, including the Public Health 
Nurse Facilitator, discussed at 12 months postintervention that the CHT had required far more facilitation than had been anticipated, and this was attributed to a lack of experience in project management and partnership working of the school nurses and health visitors at the outset.

The second theme that emerged relating to 'people' (and also to 'processes') was 'the challenge of communication.' Communication, both within and between professional groups, was viewed as a key barrier to the success of the CHT, second only to the barrier of existing heavy workloads (discussed further). The barrier of within group communication scored a mean of 4.19, 3.08 and 3.75 at baseline, 6 and 12 months, respectively (range: 1 not at all important to 5 very important). The corresponding mean scores for between group communication were 4.18, 3.86 and 3.92 .

At the outset, good communication, both within and across professional groups, was anticipated by all three groups as fundamental to the success of the CHT. Proposals included meetings arranged well in advance, wide circulation of minutes from meetings, setting up an email network and ensuring that one person from each team attended each meeting and fed back. However, by six months post-implementation, communication was an emotionally charged issue and two key challenges had emerged.

First, establishing contact with individuals was problematic due to the high numbers of part-time workers as well as the high turnover over staff within the CHT, which meant that points of contact changed. Second, was the over reliance on E-mail as the main method of communication outside of CHT meetings. Strategic PCT members felt strongly that E-mail was the best method of communication and that they should be able to assume that minutes of meetings and action plans circulated in this way would be read by CHT members. Until communication had broken down, they did not appear to have considered that accessing computers and hence E-mails would be potentially problematic for some team members:

My perception would be, which is wrong, that all health visitors would have a computer on their desk and they'd use it regularly and check their Emails regularly; and school nurses but that's just really naïve. That's just not how it works.

(Strategic post holder in PCT, FG4)

The health visitors reported sharing a computer between five nurses and stated that that E-mails were not always easy to access and hence were not always read:

Well you know honestly that is supposed to be the way forward, E-mails. We don't all have computers on our desks, you know and some of us go straight out or whatever and we don't always read E-mails.

(Health visitor, FG8)

By 12 months post-implementation, to the credit of all three groups, problems with communication appeared to have been resolved. Meetings were put into diaries well in advance and these meetings, in particular the 'away days,' were seen as useful for bringing everyone up-tospeed with the project as well as allowing discussion. One person now took responsibility for ensuring that their team was represented at each meeting and that information (including E-mails) was circulated to their colleagues.

\section{Processes}

Two themes reflected issues about 'processes.' 'The challenge of communication' was discussed above. 'Managing workloads and new ways of working' was the second emerging theme. Existing heavy workloads emerged as an important issue for all three groups over the 12 months. CHT members and wider stakeholders who completed the postal questionnaire identified this issue as the most important barrier to the success of the CHT, scoring overall a mean of 4.41, 4.50 and 4.50 at baseline, 6 and 12 months, respectively (range: 1 not at all important to 5 very important).

It was also clear from the focus groups that work associated with the $\mathrm{CHT}$ was viewed as 'additional' to existing workloads. The health visitors and school nurses stated that most of their everyday work, particularly in the case of emergencies and child protection, had to take priority over CHT work. Whilst their management was keen for the CHT to happen, it could not be at the expense of their existing work 'that we get paid for and what our team is judged on' (School 
nurse, FG8). The voluntary sector staff also talked about having to fit in CHT work as 'an extra project added onto us when we're already seriously overloaded' (Voluntary sector staff, FG9). Fortunately, there appeared to be an implicit understanding that this extra work, particularly in terms of attending CHT meetings, would be greater in the first 12 months of the project:

I think that what you have to take into account that this is a pilot and it is a learning curve and you know I certainly wouldn't see there being so many meetings in the future. We're all learning something completely new erm, and I think that maybe that's why we've had the meetings.

(Health visitor, FG5)

There was a clear, and impressive, shift from almost total independent working within the three professional groups at the start of the project towards early stage partnership working at 12 months. More specifically, by six months there was a general consensus that the different professional groups were more aware of each other's public health work, more confident in contacting each other to ask questions, and were beginning to share skills, for example, the health visitors had involved the voluntary sector in developing a health pack for parents. By 12 months, this increased awareness and sharing of skills was still developing with more examples of the health visitors, school nurses and the voluntary sector working together on specific pieces of work. These were viewed as collaborations that would not have occurred without the CHT.

We wouldn't have ever worked with the healthy living centre.

(Health visitor, FG8)

This evolving pattern of working was also identified in the questionnaire data. The impact of the CHT on ways of working, slightly increased over time but remained close to the midpoint with mean scores of 2.35, 2.38 and 3.23 at baseline, 6 and 12 months, respectively (range: 1 no change at all to 5 a lot of change). Despite the progress of the CHT over the first 12 months, it did not reach a stage whereby CHT work was integrated into everyday public health work of the three professional groups.

\section{Patterns}

Finally, two themes emerged that focused on 'patterns.' First, in discussing the 'success of the CHT, the consensus at baseline across the three groups was that the over-riding aim of the CHT was to impact on the health of the community, specifically to improve the oral health of children/ young people. However, it was generally acknowledged that it was unrealistic to expect to achieve and demonstrate real change in health outcomes (eg, a reduction in caries) in the first year of the CHT. By 6 and 12 months post-implementation, some examples of 'proxy' indicators of health improvement, for example, increased awareness of oral health messages and changes in oral health behaviour, were discussed particularly relating to the 'Bin the Bottle' campaign:

It's going to be a long time before you see any difference but I think we can say we've spoken to 148 people about dental health and given out 148 toothbrushes like we did on Friday and you know, signposted 15 people to dentists and how to access dentists and I think that's a real positive. That's a huge positive but I don't think..., it's going to be very difficult to measure what effect we've had on dental health and children.

(Health visitor, FG5)

Twelve months was suggested to be a realistic time to 'lay the foundations solidly and get people confident with the way things are going to work' (Voluntary sector staff, FG6). Indeed, at 12 months post-implementation, there were numerous examples of improved partnership working. As discussed earlier, these included CHT members now being aware of other individuals and agencies and their roles, feeling confident to approach these 'new partners,' joint working across professional roles on specific projects, for example, 'Bin the Bottle,' and a reduction in duplication of work such as delivering health information sessions in schools. The health visitors and school nurses talked about their working relationship now being as strong as it had been 15 years prior, when they had shared an office and the voluntary sector identified their increased levels of health knowledge. This new way of working was considered to have the potential for more co-ordinated working together in the future that would ultimately impact on community health. 
There was a common sense of 'feeling proud' about what had been achieved over the 12 months:

In a meeting with the health visitors she said...'we are the champions of this', and that's great ... to see themselves as champions I think is very good.

(Strategic post holder in PCT, FG7)

The second 'patterns' theme to emerge was the impact of 'outside influences' on the progress of the CHT. The emerging national agenda for public health (Department of Health, 2004) and for expanding the public health role of nurses (Department of Health, 1999; 2001b; 2004) were seen as positive by the strategic PCT members, health visitors and school nurses. Similarly, the national focus on child health (Department for Education and Skills, 2003) was recognized as an important driver of the CHT by the strategic PCT and voluntary sector staff. These Government policies were viewed as providing infrastructure, direction and an evidence-base to inform public health and child health work as well as legitimizing the inclusion of this type of work within individuals' professional roles.

In contrast, the imminent (at baseline and six months post-implementation) and current (at 12 months post-implementation) re-structuring of the PCT, with the five PCTs across the city merging to become one organization, was persistently viewed by all three groups as potentially damaging to the progress of the CHT. Members and stakeholders completing the postal questionnaire rated this issue as an important barrier to the success of the CHT, scoring overall a mean of $4.00,3.79$ and 4.00 at baseline, 6 and 12 months, respectively (range: 1 not at all important to 5 very important). The common concern was that the CHT would not be a priority of the new PCT, meaning that funding and support in the shape of the Public Health Nurse Facilitator and her administrator would disappear. To some extent these concerns appeared to be realized because at 12 months post-implementation, when the restructuring was taking place, the CHT members all mentioned that the process of agreeing a focus for the CHT for the forthcoming year was on hold:

I think to a certain extent the PCT have got the changes, erm like they're not going to do another topic now.... I don't think there's going to be anything for people to get their teeth into to push it further to develop. Although we've got to a good stage in communications and everybody's got a better understanding in future it can't go onto the next level.

(Voluntary sector staff, FG9)

One strategic PCT member remained positive about the future of the CHT:

I think if people want to maintain the enthusiasm, it will drive forward as it is.... The PCT is going to be wanting new innovative ways of working and this is a good example so I would hope the new PCT would be very receptive to it. I can see no reason at the moment why that should not continue.

(Strategic post holder in PCT, FG7)

\section{Discussion and implications for developing practice}

The purpose of this evaluation was to examine the implementation of a CHT in its first 12 months and in so doing, identify the key lessons of what worked and did not work to inform future practice. In interpreting the findings, some limitations need to be acknowledged. It is important to consider these limitations in the context of this being an evaluation in a 'real life' setting. The sample size for the postal questionnaire was small and response rates for some of the professional groups were low. We cannot be sure that the questionnaire data represent the views of nonresponders. Half of the CHT members only attended one focus group (of a possible three). The views of these individuals over the 12 months are, therefore, not captured although the opinions of their colleagues (and some of the same experiences) over this time will have been recorded. Finally, we were unable to collect data on the potential effectiveness of the Bin the Bottle campaign. However, we have collected views on the 'success' of Bin the Bottle from CHT members.

In developing and progressing the CHT, the PCT used the CMS framework that was designed for improving service delivery of clinical teams (Dartmouth Hitchcock Medical Centre, 2007). This provided a useful structure that ensured that 
a comprehensive range of issues pertinent to the development of a new team were considered from the start. For the same reason it was also a helpful framework to guide the questioning for this evaluation. Operationalizing the 'five Ps' that were developed for 'closed' clinical team settings, for example, cardiology departments, day surgery units (Golton and Wilcock, 2005) to use with the CHT, was relatively easy. Indeed, we would suggest that the CMS framework is applicable and useful in this broader public health context. The difficulty was translating theory into action when working with a virtual team made up of different organizations that in turn had different commissioners, managers, targets and working practices. Indeed, within all six emerging themes, organizational differences across the three professional groups were evident highlighting the complexity and evolving nature of public health partnership working in the community.

Perhaps, not surprisingly, the greatest challenge to the progress of the CHT was communication. Xyrichis and Lowton (2008) in their review of 10 studies on inter-professional team working in primary and community care concluded that good communication is easier to achieve when teams are based in the same premises and have a high proportion of full-time staff. Earlier research (McMurray and Cheater, 2004; Plumb, 2006) has also identified that health visitors have restricted access to computers and may have limited IT skills, meaning that relying on E-mail for communication is likely to be problematic. These issues were all pertinent to the CHT. Discussing communication processes openly at the outset and reviewing these on an ongoing basis with all team members emerged from our evaluation as vitally important in order to avoid problems at a later stage. The aforementioned potential barriers to effective communication need to be openly acknowledged and addressed early on, that is,through training or using an IT-literate team member to disseminate information from emails. Away days appear to be a useful way of keeping team members and wider stakeholders informed. Another useful approach is to designate one person in each professional group to take responsibility for ensuring that their colleagues are represented at all CHT meetings, and that information via E-mails is disseminated effectively.
Working in partnership to tackle health inequalities and improve public health is a national policy priority (Department of Health, 2000; 2001a; 2003; 2004; 2006). The CHT model, underpinned by the CMS framework, would appear to be a novel approach to progressing this at a local level. Over the duration of this evaluation there was a clear and impressive shift from almost total independent working within three professional groups (strategic post holders in the PCT, health visitors and school nurses and voluntary sector staff) at the start of the project towards early stage partnership working at 12 months. Given that the CHT was a fundamentally different way of working, it would have been unrealistic to expect more to be achieved within 12 months. It was not the aim of this evaluation to monitor changes in population health. However, 12 months into an innovation of this type, one might reasonably expect to see increased awareness of health issues, some health behaviour change and increased uptake of health services by the target population. Focus groups at 12 months provided anecdotal evidence of improved knowledge of oral health messages and switching from bottles to feeder cups by parents. Commissioners need to acknowledge that this approach requires commitment over an extended period of time before meaningful changes to population health can be expected to be demonstrated. Service level agreements would need to reflect this.

\section{Acknowledgements}

This evaluation was funded by North West Leeds PCT. We would like to thank the CHT members and stakeholders who participated in the evaluation, and Gareth Flanders who helped with data collection and analysis. We would also like to thank Francine Cheater for commenting on drafts of this paper.

\section{References}

Dartmouth Hitchcock Medical Centre. 2007: Clinical Microsystems: improving healthcare by improving microsystems. Retrieved 3 January 2007 from Dartmouth Hitchcock Medical Centre website: http://www.clinicalmicrosystem.org/

Department for Education and Skills. 2003: Every child matters. London: Department for Education and Skills. 
Department of Health. 1999: Making a difference. Strengthening the nursing, midwifery and health visiting contribution to health and health care. London: The Stationary Office.

Department of Health. 2000: The NHS plan. London: The Stationary Office.

Department of Health. 2001a: Shifting the balance of power within the NHS: securing delivery. London: The Stationary Office.

Department of Health. 2001b: Report of the Chief Medical Officer's project to strengthen the public health function. London: The Stationary Office.

Department of Health. 2002: Shifting the balance of powerthe next steps. London: The Stationary Office.

Department of Health. 2003: Tackling health inequalities: a programme for action. London: The Stationary Office.

Department of Health. 2004: Choosing health: making healthier choices easier. London: The Stationary Office.

Department of Health. 2005: Working in systems, process and systems thinking. Improvement leaders' guide. London: The Stationary Office.

Department of Health. 2006: Our health, our care, our say: a new direction for community services. London: The Stationary Office.

Director of Public Health. 2004: Public Health: a picture of public health in Leeds North West 2003-2004. Leeds: Public Health Directorate.
Fuller, S. 1999: Evaluation of pre-school oral health promotion interventions. In Watt, R., editor, Oral health promotion: $a$ guide to effective working in pre-school settings. London: Health Education Authority, 59-78.

Golton, I. and Wilcock, P. 2005: The NHS clinical microsystems awareness and development programme: final report January 2005. London: NHS Modernisation Agency.

McMurray, R. and Cheater, F.M. 2004: Vision, permission and action: a bottom up perspective on the management of public health nursing. Journal of Nursing Management 12, $43-50$.

Office of the Deputy Prime Minister. 2004: The English Indices of Deprivation 2004: Summary (revised). London: Office of the Deputy Prime Minister.

Plumb, K. 2006: Learning lessons from health visiting modernisation in Bromley. Community Practitioner 79, 400-405.

Royal College of Nursing. 2007: A paper to support the nursing contribution to public health, developed by an alliance of organisations. London: RCN.

World Health Organization. 2000: Munich declaration: nurses and midwives: a force for health. Copenhagen: WHO Regional Office for Europe.

Xyrichis, A. and Lowton, K. 2008: What fosters or prevents interprofessional teamworking in primary and community care? A literature review. International Journal of Nursing Studies 45, 140-53. 